\title{
Trabalhonecessário
}

Issn: 1808 - 799X

ano 10, no 14 - 2012

\section{O PAPEL DO BANCO MUNDIAL NA CONTRA REFORMA DA EDUCAÇÃO SUPERIOR NO BRASIL: UMA ANÁLISE DOS DOCUMENTOS QUE PRECEDERAM O REUNI}

\author{
José Renato Bez de Gregório'
}

\begin{abstract}
RESUMO
O presente artigo tem como tema central a relação direta entre as recomendações disseminadas pelo Banco Mundial desde a década de 1990 e o Decreto que estabeleceu o REUNI. Apontamos para a necessidade de observarmos este movimento não como fato isolado, mas como parte de uma estratégia burguesa de obtenção de consenso ao seu projeto de sociabilidade e de conformação da classe trabalhadora, a fim de que esta se adeque às novas necessidades do capitalismo contemporâneo, através de políticas disseminadas pelos organismos internacionais, em especial o Banco Mundial. Enfim, temos como objetivo desconstruir o argumento sustentado pelo Estado, de que o REUNI é um instrumento de democratização do acesso à educação superior pública e gratuita, ressaltando o caráter precário e ineficiente desta ampliação.
\end{abstract}

Palavras-chave: REUNI - Banco Mundial - Reforma Universitária.

\section{1 - Introdução}

Neste artigo iremos demonstrar o caráter de compartilhamento ocorrido entre a contra reforma da educação superior implantada pelos governos FHC e Lula da Silva e as diretrizes elaboradas e difundidas pelos organismos internacionais do capital, em especial o Banco Mundial, em virtude deste ter sido, historicamente um dos organismos com maior influência nas políticas de educação no Brasil. Tal compartilhamento será analisado na concepção de educação superior e de universidade apresentadas pelo BM e posta em prática pelos governos brasileiros nas duas últimas décadas, em especial a partir do Decreto n⒍096/2007 que estabeleceu o REUNI.

\footnotetext{
${ }^{1} \mathrm{O}$ autor atualmente é servidor da Universidade Federal Fluminense, mestre em Educação pela UFF e membro do GEPES/ESS-UFF. E-mail: ddpbezz@vm.uff.br
} 
Os organismos internacionais são sujeitos políticos importantes no processo de difusão do projeto burguês de dominação, contribuindo de maneira decisiva para a expansão desenfreada do capital por todos os cantos do mundo e em todas as áreas das políticas sociais dos países periféricos.

Neste trabalho tomamos o Banco Mundial como parâmetro, visto que suas ações foram e são as mais contundentes, principalmente na década de 1990, através da disseminação da ideologia neoliberal, com a publicação de documentos que advogam a contra-reforma do Estado, e os novos papéis da educação no desenvolvimento capitalista dependente dos países latino americanos.

Para tanto selecionamos alguns documentos considerados essenciais para compreensão de tal processo de difusão das concepções do Banco Mundial no que se refere à educação superior especificamente. Serão analisados: o documento de 1994 que se refere à educação superior, o de 1996 que se refere à concepção de educação como um todo, o de 1999 que destaca a preocupação do BM com o "alívio da pobreza" e a "sociedade do conhecimento", e o de 2003 que reafirma a concepção de educação do Banco na qualidade de "educação terciária".

\section{2 - O Banco Mundial: um breve apanhado histórico}

Concebido em 1944, em Bretton Woods, Estado de Novo Hampshire (EUA), o Banco Mundial inicialmente foi criado com a proposta de reconstruir a Europa após a II Guerra Mundial, com o nome de BIRD - Banco Internacional para a Reconstrução e o Desenvolvimento.

A "cooperação técnica" e financeira do BM à educação brasileira iniciou-se na segunda metade da década de 1970. Anteriormente o que ocorria era apenas uma relação entre associações de educadores brasileiros e estadunidenses para "incorporação dos ideais democráticos e constitucionais daquele país que perdurou até os anos de 1950" (FONSECA, 2000; p. 230). A partir de então essa cooperação ocorrerá através de acordos bilaterais entre os governos dos EUA e do Brasil, destinados basicamente à assistência técnica e administrados pela USAID (Agência para o Desenvolvimento Internacional do Departamento de Estado Norte-americano). 
Nos anos de 1970, os projetos do BM, que anteriormente se destinavam apenas para o financiamento de projetos relacionados à infraestrutura e energia, passam a se direcionar ao incremento da produtividade, principalmente no setor agrícola, a fim de conter o crescimento da "pobreza" (FONSECA, 2000; p. 231). A partir de então o BM direcionará suas políticas nos países periféricos para o ensino fundamental, tendo como discurso a "finalidade de assegurar aos trabalhadores o mínimo de educação a um baixo custo", concepção que perdurará até o final da década de 1990, camuflando seus reais objetivos que eram "combater" o fantasma do comunismo e defender o projeto burguês de sociabilidade.

A função principal de reconstrução dos países destruídos pela II Guerra Mundial foi cedendo seu lugar à tarefa de emprestar recursos e direcionar as políticas econômicas e sociais dos países da periferia do capitalismo.

Desde a moratória decretada pelo governo mexicano em meados da década de 1980, quando os bancos privados estadunidenses sofreram risco de colapso, o Banco Mundial encampou tais dívidas, salvando as finanças dessas corporações bancárias. A partir deste momento os países de capitalismo dependente passaram a ter como credores estes organismos internacionais. É neste contexto que surge a interferência desses organismos nas políticas econômicas e sociais de países como o Brasil, forçando a queda nos investimentos diretos, o aumento do superávit primário e o controle das taxas de inflação, a fim de garantir o mínimo de recursos para que estes honrem seus compromissos com os tais organismos, ou seja, paguem os juros absurdos cobrados por estas instituições, em particular o $\mathrm{BM}^{2}$ e o FMI.

É indispensável afirmarmos que todo o discurso neoliberal que tomou conta dos países de capitalismo dependente a partir da década de 1980 não foi por acaso, pois surgiu através da pressão dos países imperialistas em renegociar as dívidas externas desses países e de uma opção política consciente da burguesia brasileira que aderiu ao projeto burguês internacional. Para sustentarmos tal argumento, basta nos remetermos aos próprios documentos do Banco, onde brasileiros são citados como colaboradores e consultores do BM, dentre eles diversos nomes que detinham cargos no primeiro escalão dos governos Collor de

\footnotetext{
${ }^{2}$ Para aprofundar a análise da história do BM e sua relação com os governos brasileiros ver FONSECA
} (2000) e TOUSSAINT (2007). 
Mello, FHC e Lula da Silva. Destacam-se nesta tarefa nomes como Claudio Moura e Castro e Luiz Carlos Bresser Pereira; o primeiro até hoje continua envolvido em ações no Ministério da Educação e o segundo foi por muitos anos Ministro do governo FHC, sendo o responsável maior pela implantação da política neoliberal no país através da contra-reforma do Estado brasileiro.

Para sustentar todo esse mecanismo, o Banco divulga os documentos que iremos analisar, sempre apontando diretrizes a serem seguidas pelos países capitalistas periféricos, como sendo "tábua de salvação" para seus problemas. Num primeiro momento, a contra-reforma da educação superior, que está inscrita na contra-reforma da educação e do próprio Estado brasileiro.

Apresentaremos a seguir os aspectos centrais dos principais documentos elaborados pelo BM nos anos de 1990 e início do novo século.

\section{3 - O Documento de 1996 e as Recomendações Gerais para a Educação}

Para uma melhor compreensão da interferência dos organismos internacionais nos sistemas educacionais dos países periféricos e principalmente no Brasil, recorremos inicialmente ao documento de 1996, intitulado "Prioridades e Estratégia para a Educação". Tal documento apenas ratifica todas as propostas apresentadas na "Conferência Mundial de Educação Para Todos", realizada em Jomtien na Tailândia no início dos anos 1990, patrocinada pelos organismos internacionais, dentre eles o Banco Mundial, que apresentava o ensino fundamental como sendo a principal preocupação desses organismos em relação aos países periféricos. Na verdade tal preocupação tem três razões principais: a) a primeira refere-se ao alívio das tensões sociais causadas pelo endividamento desses "países pobres" atingindo a massa dos trabalhadores; b) a segunda diz respeito à articulação das políticas de "alívio da pobreza" com a diminuição dos gastos com a educação superior, colaborando para o aumento do superávit primário e consequentemente com o pagamento dos juros das dívidas externas dos "países pobres"; c) e por fim a terceira razão é diretamente ligada à abertura de novas oportunidades para o capital se reproduzir, com a ampliação dos mercados referentes à educação superior.

Neste texto o Banco Mundial atribui à educação o papel de resolver os problemas econômicos resultantes das transformações que vem acontecendo no mercado de trabalho desde a década de 1970. Para o BM, cabe à escola o papel 
de formar "cidadãos" preparados para constantes mudanças de emprego, capazes de se adaptar facilmente a estas mudanças. Segundo o documento, estes "cidadãos" devem estar preparados para atender a crescente demanda por "trabalhadores adaptáveis", e estes precisam adquirir sem dificuldade novos conhecimentos durante toda a vida e expandir constantemente seus conhecimentos.

O Banco afirma que o principal ativo que os "pobres" possuem é o seu trabalho, e que por isso devem se concentrar no seu uso produtivo para "reduzir" tal "pobreza". Neste sentido, a educação, sobretudo o ensino fundamental deve servir para aumentar a produtividade deste trabalho, além de reduzir a taxa de natalidade e melhorar a saúde destas pessoas.

Portanto, como já identificamos anteriormente, o BM mais uma vez reforça que naquele momento, os governos deveriam concentrar seus recursos na promoção do ensino fundamental, pois esta agrega "conhecimentos gerais como a linguagem, as ciências, a matemática e a capacidade de comunicação, que proporcionam a base para a educação e capacitação posteriores." (Banco Mundial, 1996; p. 2) E continua afirmando a importância do ensino fundamental para a formação necessária para desempenhar as funções no local de trabalho.

E o documento segue relatando que os gastos governamentais com a educação são "ineficientes e pouco equitativos" e que os gastos com a educação superior seguem altos e, portanto devem diminuir, visto que os estudantes deste nível provem de famílias ricas, com capacidade de financiarem eles próprios os seus estudos. Essa diminuição no gasto do governo com a educação superior geraria um remanejamento de verbas públicas para financiar o ensino fundamental.

O BM defende ainda o pagamento de mensalidades pelos alunos nas universidades públicas, indicando a tendência a um processo de privatização do sistema universitário federal.

$\mathrm{Na}$ passagem a seguir, o BM deixa claro que as prioridades educacionais devem ser estabelecidas, levando-se em conta análises de indicadores econômicos, através de normas estabelecidas e de resultados mensurados, comparando a relação custo-benefício.

"As prioridades educacionais devem estabelecer-se tendo em conta os resultados, utilizando análises econômicas, estabelecendo normas e medindo resultados através da avaliação da aprendizagem (...) geralmente se comparam os 
benefícios (em produtividade da mão de obra, medida pelos salários) com os custos para as pessoas e para a sociedade. Se identificam como prioridades dos investimentos públicos, os investimentos para os quais a taxa de rendimento social é mais alta e o nível de subsídio público é mais baixo." (BANCO MUNDIAL, 1996; p. 10, tradução nossa)

Por fim o documento volta seu ataque aos sindicatos de professores, às associações de alunos, às elites dominantes e à setores do próprio governo, como sendo empecilhos à tais reformas educacionais. Ao defender a universidade pública e gratuita, essas instituições sindicais passam a ser vistas pelo Banco Mundial como um obstáculo a ser transposto e para isso passam a ser classificadas como defensoras de privilégios corporativistas e elitistas. Essas entidades são apontadas como beneficiárias de tal sistema educacional, considerado arcaico pelo BM.

O Banco segue afirmando seu "compromisso" com o ensino fundamental, porém destaca que quando atingido os níveis universais de qualidade e equidade poderá financiar projetos de educação superior desde que estes sejam para torná-la mais eficaz e menos dispendiosa, ou seja, está de acordo com as diretrizes apontadas pelo Banco em seus documentos, dando ênfase a participação de capital privado, que servem aos interesses da classe burguesa.

\section{4 - Recomendações para o Ensino Superior: o documento de 1994}

Pouco tempo antes, mais precisamente em 1994, o Banco Mundial já havia manifestado sua opinião sobre quais deveriam ser as diretrizes a serem seguidas pelos países do capitalismo periférico em relação ao ensino superior. Mais uma vez constatamos a presença da relação custo/benefício como sendo a base dos argumentos apresentados pela instituição.

È importante ressaltar que tal fenômeno não aconteceu isoladamente com - Brasil. Quase a totalidade dos países periféricos sofreu influência dos organismos internacionais nas décadas de 1980 e 1990, uns um pouco mais cedo e outros mais tardiamente como o caso do Brasil.

Esse documento de 1994 serve para mostrar como o próprio título diz "As Lições Derivadas da Experiência", apresentado estudos de casos e ações isoladas em diversos países, que segundo o ponto de vista do Banco Mundial, deveriam ser tomadas como exemplo a ser seguido pelos países periféricos. 
É interessante o fato de a instituição reconhecer a importância do ensino superior, porém a finalidade deste ensino e a maneira como ele deve ser oferecido à população é que surge como ponto crucial de nossa crítica. Em nenhum momento a educação superior surge como elemento de formação crítica do ser humano, mas sim como: a) formação de força de trabalho para servir aos interesses da burguesia; b) campo de exploração para o capital privado e; c) difundir a concepção burguesa de mundo. (LIMA, 2007)

Segundo o documento do Banco, o objetivo das instituições de ensino superior dos países periféricos deve ser apenas o de "transferir, adaptar e divulgar conhecimentos gerados em outras partes". (BANCO MUNDIAL, 1994; p.1, tradução nossa) Estas instituições serviriam ainda para prestar serviços de assessoria e consultoria a empresas privadas.

$\mathrm{Na}$ página 2 deste documento surge claramente a preocupação que marcou os documentos do BM na década de 1990, referente à relação custo/benefício. O documento cita o "esforço feito por diversos países, tanto industrializados como em desenvolvimento, para resolver o problema da educação superior" a fim de "melhorar a qualidade e ao mesmo tempo de diminuir os gastos por estudantes". (BANCO MUNDIAL, 1994; p.2, tradução nossa)

Em seguida reafirma a opinião dos organismos internacionais, que apontam o ensino superior dos países periféricos como sendo "elitista", e que este beneficia apenas indivíduos provenientes de "famílias acomodadas". É necessário destacar a orientação dada pelo BM, recomendando cautela na implantação dessas reformas educacionais, pois podem afetar diretamente famílias que detém o poder econômico nestes países e desencadear um processo de instabilidade dos regimes políticos. Sabemos que tais tensões dentre as diversas frações burguesas são inerentes ao capitalismo e que, portanto, os governos que servem ao capital estarão sempre prontos para mediar tais conflitos.

O Banco constata que os recursos por estudantes do ensino superior vêm diminuindo nos países pobres e que o problema se agrava pelo uso ineficiente destes recursos. E cita como exemplo de ineficiência os gastos com alimentação e moradia estudantil. Para o BM tais "privilégios" devem ser suprimidos. Sabemos que tal medida impediria o acesso ao ensino superior de uma substancial camada da população proveniente de pequenas cidades do interior e da periferia dos grandes centros, que consegue chegar á universidade pública, pois além de não 
ter condições de manterem-se nas imediações geográficas da instituição devido ao alto custo de moradia e de alimentação, precisarão trabalhar para conseguirem sobreviver.

Logo após tal afirmação, o documento aborda um aspecto primordial para nossa análise, que é a relação entre o quantitativo de estudantes e o de docentes, que é considerada baixa pelo BM, e a subutilização das instalações físicas.

Outra preocupação do BM que podemos apreciar no documento de 1994, se refere aos altos índices de reprovação, repetição e evasão apresentados no ensino superior nos países pobres. O documento diz:

"Em muitos países em desenvolvimento o ensino superior se caracteriza pela baixa relação entre estudantes e pessoal docente, serviços subutilizados, duplicação de programas, elevadas taxas de deserção e repetição, e uma proporção muito alta de gastos destinados a atividades não educacionais, como moradia, alimentação e outros serviços subvencionados para os estudantes." (BANCO MUNDIAL, 1994; p.3, tradução nossa)

O documento de 1994 segue com suas orientações para o ensino superior e nos chama atenção o fato de recomendar o aumento no número de matrículas na educação superior, sem que haja o incremento de recursos para isso.

Afirma que o modelo europeu de universidade de pesquisa é "muito custoso e pouco apropriado" para os países do "capitalismo em desenvolvimento". Deve-se fomentar um novo modelo de ensino superior, mais diversificado, com maiores investimentos privados, que atenda a crescente demanda social e se adapte as constantes mudanças do mercado de trabalho. Em outras palavras podemos afirmar que o que o BM tenta difundir em seu "manual de instruções" é que o padrão a ser seguido é o modelo estadunidense de universidade, baseado na diversificação de instituições e cursos e que os países periféricos não devem desenvolver pesquisa e desenvolvimento a fim de alcançar novas tecnologias, mas apenas se moldarem as mudanças do mercado de trabalho a fim de atenderem as necessidades do capital.

A diversificação de modelos de instituições de ensino superior é mais um ponto que o Banco incentiva insistentemente. Como afirmamos anteriormente, o BM considera o modelo europeu de universidade de pesquisa ineficiente e altamente custoso e para tal oferece como alternativa a expansão de faculdades isoladas, centros universitários, cursos politécnicos, institutos profissionais e técnicos de curta duração e a elaboração de cursos á distância. 
"O modelo tradicional de universidade européia de pesquisa, com sua estrutura de programa de um só nível, tem demonstrado ser custoso e pouco apropriado no mundo em desenvolvimento. A maior diferenciação na educação superior, o desenvolvimento de instituições não universitárias e 0 fomento de estabelecimentos privados, pode contribuir para satisfazer a crescente demanda social por educação pós-secundária e fazer os sistemas de nível terciário serem mais sensíveis às necessidades mutantes do mercado de trabalho." (BANCO MUNDIAL, 1994; p. 5, tradução nossa)

O Banco reconhece ainda a importância do apoio às instituições privadas que para ele, podem aumentar o número de vagas no ensino superior com "pouco ou nenhum custo para o Estado". Cita também o caso de alguns países como o Chile, que oferecem incentivos fiscais para instituições privadas que ofereçam vagas para o ensino superior.

Além disso, o BM insiste na participação dos alunos no financiamento da educação pública de nível superior, seja através da cobrança de mensalidades, ou através de formas recompensatórias de ex-alunos, como doações ou prestação de serviços públicos gratuitamente.

$O$ incentivo à captação de recursos externos por parte das instituições de ensino superior públicas também é indicado pelo organismo. A associação entre instituições públicas e empresas privadas para fins de consultoria, oferecimento de cursos pagos e realização de pesquisas encomendadas é apontada como solução para o aumento da captação de recursos para as universidades públicas.

"Em resumo, o maior apoio financeiro privado para a educação superior mobilizado mediante a eliminação de subsídios não relacionados com a instrução, a cobrança de mensalidades, a obtenção de doações e a realização de atividades que gerem recursos, podem proporcionar às instituições uma base de financiamento mais diversificada e provavelmente mais estável." (BANCO MUNDIAL, 1994; p. 8, tradução nossa)

Podemos observar ainda a recomendação por parte do BM para a criação de mecanismos de avaliação e fiscalização por parte do governo para que possa controlar as metas estabelecidas de eficácia e desempenho, condicionando a distribuição dos recursos aos resultados obtidos pela instituição nos programas de avaliação deste desempenho.

"Na maioria dos países, a distribuição dos recursos estatais às instituições de nível terciário se baseia em pressupostos negociados. Este sistema não proporciona incentivos para o funcionamento eficiente e o melhoramento da qualidade, e torna difícil ajustar a distribuição dos recursos financeiros às circunstâncias mutáveis. Cada vez mais se estão utilizando outros mecanismos que vinculam o financiamento a critérios de desempenho nos países da OCDE, e que poderiam ser considerados também nos países em desenvolvimento." BANCO MUNDIAL, 1994; p. 9, tradução nossa) 
Existe também a defesa do Banco ao sistema de vouchers, onde os estudantes recebem vales educacionais do governo, que podem ser utilizados em qualquer instituição que estes escolham, caracterizando uma clara transferência de recursos do Estado para a iniciativa privada, sob o pretexto de promover a igualdade entre os estudantes, mediante medidas focalizadas, conforme passagem abaixo nos mostra:

"Também se pode melhorar a equidade mediante planos de subsídios focalizados aos estudantes do grupo de recursos mais baixos e através de programas de trabalho e estudo. Os programas de assistência financeira que serão administrados por um órgão central (como nos EUA e no Reino Unido), e que permitam aos estudantes utilizar seus planos de assistência em qualquer instituição que eles escolham..." (BANCO MUNDIAL, 1994; p. 9, tradução nossa)

E prossegue apresentando a suposta necessidade de criação de organismos para fiscalizar a atuação das instituições de ensino superior, a fim de garantir "um marco jurídico bem definido" e "políticas coerentes" com o objetivo de transformar a educação superior em um mercado disponível para a exploração do capital, como fora feito com outras áreas como saúde e infraestrutura. Esse órgão de fiscalização funcionaria como agência reguladora, garantindo autonomia às universidades públicas em setores administrativos considerados chave, como a cobrança de mensalidades, captação de recursos junto à iniciativa privada e a contratação de demissão de pessoal.

A partir daí, o que se vê é uma mudança de rumo na estratégia dos organismos internacionais como veremos na análise do documento do BM de 1999.

\section{5 - Estratégias para o Setor Educacional: o documento de 1999 e uma mudança no discurso}

A primeira característica do documento de 1999 que nos salta aos olhos é a análise não tão centrada com a relação custo/benefício, presente nos estudos do BM em toda a década de 1990, passando a uma visão mercantil e comercial. Neste momento o que nos parece mais importante para o Banco Mundial é fazer com que os governos se adéquem ao discurso da "sociedade do conhecimento", se referindo à educação como fator primordial para o desenvolvimento e a competitividade das nações no mundo dito "globalizado". A educação superior é posta como fator importante de "alívio da pobreza" e torna-se importante instrumento de coesão social. 
"A educação determinará quem tem as chaves dos tesouros que o mundo pode fornecer. Isso é particularmente importante para os mais pobres, que têm que confiar no seu capital humano como o principal, se não o único, meio para escapar da pobreza" (BANCO MUNDIAL, 1999, p.1, tradução nossa)

Cabe um parêntese para ressaltarmos uma constatação de que o conceito "pobreza"3 assumiu centralidade nos documentos de formulação de políticas públicas para os países do capitalismo periférico. Segundo Ugá:

".... que poderia ser visto como uma mudança de política - de uma política apenas voltada para o ajuste fiscal, para uma política mais 'social' (por meio de um 'combate a pobreza') - faça parte da própria lógica do marco teórico do neoliberalismo: políticas focalizadas e compensatórias voltadas para os 'pobres'." (UGÁ, 2004; p.55)

A preocupação do BM com o "alívio da pobreza" vem da necessidade do neoliberalismo tratar as conseqüências negativas do duro ajuste estrutural que o capitalismo optou por aplicar nos países periféricos ${ }^{4}$, gerando aumento da informalidade no trabalho e do desemprego. Portanto a "pobreza", definida pelo BM com "a incapacidade de atingir um nível de vida mínimo" (UGÀ, 2004; p. 58), só pode ser aliviada através de políticas focalizadas e compensatórias, visando aumentar a capacidade de consumo desses indivíduos (programas de complementação de renda) e superando a "incapacidade" desses indivíduos através da abertura de oportunidades econômicas (aumento do capital humano ${ }^{5}$ ) e da prestação de serviços sociais mínimos (saúde e educação).

Neste documento de 1999, percebemos que o BM redireciona seu foco para o ensino superior, reconhecendo sua importância, porém defendendo outra linha de financiamento e outra estrutura para a oferta desse nível de ensino. A partir de então o Banco passa a incentivar os investimentos do setor público na expansão do ensino superior associado a ampliação do setor privado, através da transferência de recursos públicos para o setor privado via créditos educativos (vouchers), baseando sua argumentação principalmente no direito de "escolha dos indivíduos" e em "preços mais acessíveis". Nota-se uma clara intenção do BM em abrir os mercados do setor educacional para a exploração do capital privado,

\footnotetext{
${ }^{3}$ Para um maior aprofundamento sobre a categoria "alívio da pobreza" nos moldes utilizados pelo Banco Mundial, consultar UGÁ (2004).

${ }_{5}^{4}$ Para aprofundar análise sobre ajuste estrutural ver CHOSSUDOVSKY (1999).

${ }^{5}$ A teoria do Capital Humano afirma que a diferença de rendas entre os indivíduos é diretamente relacionada ao nível de investimento que o próprio indivíduo faz em si mesmo (principalmente através da educação). Segundo esta teoria o principal bem dos pobres é o tempo para trabalhar; ao educar-se o indivíduo aumenta a produtividade do seu trabalho, conseguindo assim melhores salários no competitivo mercado de trabalho.
} 
transformando o ensino superior em mercadoria, transferindo a maior parte dos custos para as famílias dos estudantes.

Além de defender a diversificação de instituições, o BM deixa claro que as instituições de ensino caracterizadas pela indissociabilidade entre ensino, pesquisa e extensão, não devem mais ser o predominante. Poucas universidades devem se dedicar a pesquisa e atender exclusivamente à elite intelectual do país, relegando aos trabalhadores as instituições que enfoquem apenas o ensino. As primeiras seriam financiadas prioritariamente com verbas públicas, já as segundas caberiam ao setor privado.

Neste caso o objetivo que se deixa transparecer é o de controlar com maior facilidade o cotidiano das salas de aulas, padronizando os conteúdos através de currículos e avaliações, engessando a pesquisa nacional, tornando países como o Brasil, ainda mais dependentes tecnologicamente dos países centrais, e consequentemente os forçando a consumir pacotes educacionais e tecnológicos produzidos por esses países.

Segundo o documento de 1999, os "países pobres" devem desenvolver pesquisas apenas em áreas onde possuem alguma vantagem comparativa, e dessa forma jamais atingirão patamares de tecnologia de ponta, garantindo aos países do capitalismo central a vantagem nas relações comerciais, na medida em que estes produzem mercadorias com um valor agregado infinitamente superior às mercadorias oferecidas pelos países periféricos, em geral produtos agropecuários, ou no máximo agroindustrializados.

E mais uma vez as aparecem previsões para os "países pobres" que se negarem a seguir tais recomendações, classificados pelo Banco como antiquados.

"As escolhas que os países fazem agora, terão reflexos a longo prazo. Os que
responderem rapidamente farão progresso, os que não, se arriscam a ficar para
trás. As disparidades educacionais entre os países já são grandes - muitos ainda
estão lutando para fornecer livros básicos, quadro-negro e prédios escolares,
enquanto outros estão adotando rapidamente novas tecnologias de informação e
de educação." (BANCO MUNDIAL, 1999, p. vi, tradução nossa)

Pode-se encontrar também neste documento de 1999 uma tendência á implantação em massa do ensino à distância, tanto como forma de treinamento (não formação) de professores em serviço, quanto como instrumento de massificação do ensino superior a baixo custo. 
Percebe-se outra tendência neste documento, quando se refere à educação em passos graduais, onde segundo o BM, os "países pobres" devem primeiro universalizar a educação básica (leia-se ensino fundamental), para depois sim investir nos níveis seguintes, sob a alegação de que não há tempo nem recursos financeiros disponíveis para atender a todos os níveis concomitantemente. $O$ investimento na educação básica está entre as mínimas concessões feitas aos países periféricos, limitados aos parcos recursos disponíveis a estes, a fim de garantir a coesão social em torno das reformas estruturais elaboradas pelos organismos internacionais e implantadas pelas burguesias locais. Como resultado, os países do capitalismo periférico jamais poderão atingir recursos tecnológicos próprios ou desenvolver C\&T, assim como recursos materiais e intelectuais relacionados com seu ambiente social, cultural, geográfico, religioso, étnico e político. A capacidade local para proposições e criação de instrumentos educacionais fica de maneira muito severa comprometida, colaborando para uma uniformidade que agrava a dependência externa.

Portanto, resumidamente o que vemos neste documento de 1999 é a preocupação do BM em garantir a mercantilização e a padronização do conhecimento, a fim de transformá-lo em produto negociável em qualquer parte do mundo, abrindo novos mercados para os investidores internacionais interessados em se apropriar dos lucros gerados por mais esta frente capitalista.

\section{6 - Documento de 2003: "Sociedade do conhecimento e educação terciária"}

O documento de 2003 do BM intitulado "Construir Sociedades do

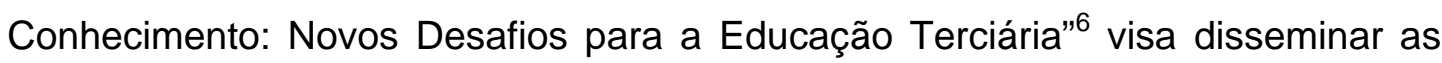
idéias do Banco referentes a importância da formação pós-média para o desenvolvimento econômico dos países do capitalismo periférico e como o melhoramento da educação "terciária" pode contribuir para a estratégia global do Banco de "redução da pobreza", cumprindo as metas de desenvolvimento das Nações Unidas (ONU) para o milênio. Devemos, sempre destacar que tal importância propalada pelo BM refere-se à educação nos moldes do capital,

\footnotetext{
${ }^{6}$ O Banco Mundial utiliza a definição de Educação Terciária criada pela OCDE (Organização de Cooperação para o Desenvolvimento Econômico) como sendo o nível de estudos após o ensino médio.
} 
sempre destacando a relevância de um processo de aprendizagem continuada e da construção da "sociedade do conhecimento", conforme passagem abaixo:

"No marco atual do processo de aprendizagem continuada, a educação terciária brinda não só as destrezas de alto nível que exigem os diversos mercados de trabalho, como também o aperfeiçoamento de professores, médicos, enfermeiras, funcionários públicos, engenheiros, humanistas, empresários, cientistas, sociólogos e especialistas dos diferentes campos do saber." (BANCO MUNDIAL, 2003; p.ix, tradução nossa)

A partir de então o BM desloca o eixo da educação superior para a educação terciária, sendo esta definida por tudo aquilo que possa vir depois do ensino médio. Este novo padrão de ensino pós-médio terá que se estabelecer de diversas maneiras e apresenta-se como "uma "alternativa realista" capaz de massificar à graduação e, cada vez mais, a pós-graduação" (LEHER e BARRETO, 2008; p. 433). Diversas modalidades de cursos pós-médios deveriam ser implantados, desde universidades virtuais para ministrar o ensino a distância até a reforma curricular para a criação de cursos aligeirados. A presença empresarial é vista como muito importante para criar um ambiente favorável ao mercado, porém a chancela estatal também torna-se imprescindível a fim de marcar tais iniciativas com um "selo de qualidade" (LEHER e BARRETO, 2008).

A formação aligeirada a fim de massificar a educação terciária proposta pelo BM, seria implementada através da criação de ciclos básicos, nos moldes dos community colleges - cursos genéricos de dois ou três anos, podendo ou não ser vocacionais, seguida de uma segunda etapa que seria reservada apenas para os especialmente talentosos, de natureza profissionalizante. Dependendo do "talento", o estudante pode cursar mais um ano e licenciar-se para o magistério, nos moldes das chamadas licenciaturas curtas. Estudantes especialmente talentosos poderiam cursar as carreiras mais prestigiosas, de quatro ou cinco anos adicionais, ou mesmo dirigir-se à pós-graduação stricto sensu.

O Banco continua e destaca a importância das universidades neste processo de aprendizagem continuada e de produção do conhecimento para o desenvolvimento capitalista, porém amplia a concepção de diversificação das instituições de ensino superior, ressaltando a importância das escolas técnicas, dos laboratórios de pesquisas, dos community colleges, dos centros de excelência, dos centros de educação à distância, entre outros.

O documento de 1994 é citado como tendo sido um marco importante para o Banco, tendo servido de parâmetro para a definição de políticas e como 
referência para a participação contínua do BM nas políticas de educação superior, tornando-as, no seu modo de ver, mais eficiente, pertinente, transparente e receptiva. Entretanto destaca que algumas alterações no mundo do capital, o fizeram rever algumas posições referentes à maneira de encaminhar as políticas de educação superior:

\begin{abstract}
"Desde a publicação do estudo em 1994, o conhecimento se converteu, mais que nunca, em um fator primário de produção em todo o espectro da economia mundial. As recentes transformações que se tem produzido no mundo e na educação terciária tem feito reexaminar as políticas e hipóteses para divulgar o trabalho realizado em um setor que atravessa uma contínua e acelerada transformação. Sem dúvidas, a velocidade da mudança e da inovação tem se intensificado de maneira notória. Assim como o ciclo de desenvolvimento dos produtos tem se reduzido, os serviços representam hoje uma parcela muito maior da produção econômica mundial, a potência e a capacidade do computadores continuam crescendo a medida que seus preços baixam, os custos de transmissão de dados diminuem e a tecnologia da comunicação se expande, especialmente nos países em desenvolvimento. A educação terciária e, em, particular, seu papel na capacitação, na pesquisa e na informação, é um fator vital para que os países possam se adaptar as mudanças de longo prazo." (BANCO MUNDIAL, 2003; p. $x$, tradução nossa)
\end{abstract}

A discussão segue afirmando o caráter "atrasado" das universidades dos "países em desenvolvimento e em transição", que devem se adaptar as novas tecnologias da informação e da comunicação (TIC's), mudando seus modos de "operação e prestação de serviços".

Diante da necessidade de expansão do ensino pós-médio, o BM aponta que esta deve acontecer com financiamento sustentável, reduzindo as desigualdades de acesso e garantindo resultados adequados à "sociedade da informação".

O Banco reafirma a preocupação com o desenvolvimento econômico e com a "redução da pobreza", e aponta algumas novas tendências as quais os países periféricos devem dar ênfase especial:

- O conhecimento como principal motor do desenvolvimento econômico;

- A aparição de novos provedores de educação (educação sem fronteiras);

- A mudança nos padrões da educação dita terciária devido às novas tecnologias;

- A aparição das forças do "mercado educacional", concebido como um mercado global do capital humano;

- O aumento na procura dos países periféricos por apoio financeiro e técnico do BM;

- A visão equilibrada e integral da educação para a criação do capital humano como "bem público global".

\footnotetext{
${ }^{7}$ O Banco Mundial usa tal denominação para se referir aos antigos países comunistas.
} 
Entre os objetivos do documento, destaca o fato do Banco outorgar ao Estado a responsabilidade de estabelecer um marco favorável que impulsione as "instituições de educação terciária" a serem mais "inovadoras" e a responder melhor as necessidades de uma economia do conhecimento globalmente competitiva, assim como as novas exigências do mercado de trabalho, ou seja, o Estado deve ser o responsável por criar instrumentos legais e institucionais, a fim de favorecer os interesses do capital, através de uma conformação da força de trabalho às necessidades da economia.

\begin{abstract}
"As instituições de educação terciária são coerentes com as estratégias de crescimento econômico baseado no conhecimento, assim como de redução da pobreza, já que contribuem para: a) capacitar força de trabalho qualificada e adaptável, de alto nível, que inclui cientistas, profissionais, técnicos, professores da educação básica e secundária e futuros dirigentes governamentais, empresariais e da sociedade civil; b) gerar novos conhecimentos; e c) construir a capacidade de chegar ao conhecimento global e adaptá-lo ao uso local. As instituições de educação terciária são únicas enquanto a sua capacidade de integrar e criar sinergia entre as três dimensões citadas." (BANCO MUNDIAL, 2003; p xx, tradução nossa)
\end{abstract}

Segundo o BM, as inovações tecnológicas e a difusão das inovações científicas, inclusive a pesquisa de base, servem apenas para aumentar a produtividade da economia, ou seja, o fortalecimento das habilidades dos trabalhadores é insumo para o aumento qualitativo da força de trabalho desde que permita o referido aumento de produtividade. E o Banco continua seu discurso afirmando que além das vantagens econômicas, a "educação terciária" colabora para uma maior coesão social, contribuindo para um "diálogo aberto e democrático", valorizando a diversidade em termos de gênero, étnica, religiosa e social.

O Estado deve promover a "equidade" entre os indivíduos, evitando que parcela da população que possui "méritos acadêmicos suficientes" seja impedida de ingressar na educação terciária por desvantagem econômica. Para tal o Estado deve fornecer meios de financiamento estudantil para que estas pessoas "excluídas" do processo tornem-se capazes de ingressar neste nível de ensino pós-médio.

Outro importante papel da "educação terciária", segundo o BM, é a formação de professores e diretores escolares para uma maior capacidade na "elaboração de currículos", na "pesquisa sobre ensino e aprendizagem" na "gestão econômica dos recursos" para a educação básica. Neste momento o BM revela a sua preocupação com a formação dos quadros de professores da educação básica, a fim de disseminar as idéias deste organismo, perpetuando o projeto de dominação burguesa sobre os países periféricos através da conformação dos docentes, 
formadores de opinião e responsáveis pela formação dos futuros trabalhadores do país, naturalizando as práticas educacionais defendidas pelos países centrais.

$\mathrm{O}$ documento chega ao absurdo de recomendar que as normas para a criação de novas instituições e novos cursos devem ser "flexibilizadas e restringir-se a requisitos mínimos, a fim de não se gerar barreiras de acesso ao mercado" (BANCO MUNDIAL; 2003; $p x x v$, tradução nossa).

Deverá também, segundo o documento do Banco, haver uma ampliação da diversificação no financiamento das instituições públicas, gerando novas formas de captação de recursos que não seja apenas o fundo público, mas também recursos provenientes das famílias dos estudantes (cobrança de mensalidades), de ativos institucionais (cursos pagos e consultorias a empresas) e de doações de empresas privadas (sempre com algum interesse econômico).

Podemos seguir enumerando características deste documento de 2003, dentre elas as previsões para àquele país que não seguir as diretrizes apontadas pelo banco. Segundo o informe, os países que não fizerem os investimentos suficientes na "educação terciária" nos moldes do BM sofrerão com a diminuição da capacidade de competir com eficiência nas economias regional e global, com o aumento das desigualdades econômicas e sociais, com a diminuição da qualidade de vida e com a deterioração da saúde e da expectativa de vida, provocando um aumento dos gastos sociais do governo com programas de bem estar social, além de uma debilidade da coesão social. E continua:

"não se pode conseguir uma transformação e um crescimento sustentável nos diversos campos da economia se não existe um sistema de educação terciária inovador que contribua para construir uma capacidade de absorção necessária para que o investimento do setor privado e o recurso dos contribuintes produzam um impacto produtivo e duradouro" (BANCO MUNDIAL, 2003; p. xxiv, tradução nossa)

E ainda propala que, aliado à recomendação de associação ao capital privado, deverá haver uma "distribuição de forma mais equilibrada" dos recursos e que o investimento nos três subsetores da educação siga uma "sequência adequada ao nível de desenvolvimento educativo, ao padrão de crescimento econômico e à situação fiscal do país", ou seja, para os países centrais haverá um padrão educacional e para os países periféricos outro, muito provavelmente de acordo com sua realidade econômica. Além disso, ressalta que os países periféricos aplicam de maneira ineficiente seus recursos na educação terciária, citando o exemplo dos subsídios estudantis (moradia e alimentação) como sendo gastos que 
poderiam estar sendo "melhor direcionados" se fossem aplicados em equipamentos, materiais pedagógicos e recursos bibliotecários. Chama a atenção o fato de o BM não citar o fator remuneração dos recursos humanos como importante na qualidade do ensino.

No ponto de vista do BM, o simples fato de direcionar vultosas quantias para a ciência e tecnologia, não significa que necessariamente se conseguirá bons resultados econômicos, e cita o caso de países como o Brasil, a Índia e os países do antigo bloco soviético como exemplos de ineficiência por não possuírem "um sistema completo de instituições e práticas conhecido como sistema nacional de inovações" (BANCO MUNDIAL, 2003; p. 28, tradução nossa), ou seja, um sistema de C\&T voltado exclusivamente para atender aos interesses do capital ${ }^{8}$.

Por fim podemos identificar as diretrizes básicas do Banco Mundial em relação aos países periféricos, sempre salientando que a estabilidade econômica e política são fundamentais para as ações do capital internacional que deseja se estabelecer nesses países, baseados nas reformas educacionais que devem ser promovidas por estes governos nos moldes defendidos pelo Banco, como facilmente poderemos constatar no caso brasileiro:

- Introduzir currículos mais flexíveis e menos especializados;

- Promover programas e cursos de curta duração;

- Criar um marco regulatório adaptável;

- Estabelecer sistemas de financiamento público que ajudem as instituições privadas e públicas a responder as demandas do mercado;

- Melhorar o acesso através de financiamento estudantil para instituições privadas;

- Buscar participação externa na gestão dos assuntos públicos;

- Profissionalizar a gestão universitária;

- Ampliar a oferta de cursos à distância;

- Criar cursos com base da demanda;

- Incluir formação permanente ao pessoal docente e diretivo no sentido de uma gestão empresarial nas instituições de ensino superior públicas;

- Combinar instituições públicas e privadas a fim de minimizar os custos;

- Investir em pesquisa em algumas áreas selecionadas, onde haja alguma vantagem comparativa para o desenvolvimento econômico do país.

Portanto, não é difícil identificar cada uma dessas diretrizes do capital internacional para o sistema educacional superior dos países da periferia do capitalismo, em especial no caso brasileiro contidas no REUNI, porém é importante

\footnotetext{
${ }^{8}$ O sistema de C\&T passa a ser CT\&I, onde a inovação passa a ter importância relevante para o desenvolvimento industrial. Para aprofundar ver OLIVEIRA (2002).
} 
entendermos que não se trata de imposição do BM, mas sim do compartilhamento de interesses, das concepções de educação e de universidade que parte tanto de fora para dentro, quanto de dentro para fora do país.

Destas análises podemos concluir que os organismos internacionais, financiados e com sede nos países do capitalismo central são os instrumentos que essas potências utilizam de forma freqüente para ditar as diretrizes a serem adotadas pelos países do capitalismo dependente ${ }^{9}$. Essas instituições ditas multilaterais, impõem metas e políticas a serem implementadas e atingidas pelos países periféricos, para que esses tenham acesso a empréstimos e financiamentos para desenvolver o projeto de dominação de sua burguesia local, associada a burguesia internacional.

Segundo nos mostra Harvey (2003), o acesso ao conhecimento científico e técnico sempre teve importância na luta competitiva, porém as informações precisas e atualizadas são, também agora, uma mercadoria muito valorizada, o acesso à informação, bem como o seu controle, aliados a uma forte capacidade de análise instantânea de dados tornaram-se essenciais. O conhecimento da última técnica implica a possibilidade de alcançar uma importante vantagem competitiva. $\mathrm{O}$ saber passa a ser uma mercadoria-chave, a ser produzida e vendida a quem pagar mais. Assim, universidades e institutos de pesquisas competem vorazmente.

Devido à crise atual do capitalismo, a busca por novas áreas de exploração é incessante, e o campo educacional surge como um grande filão para investimentos do capital internacional, principalmente nos países do capitalismo periférico. E a burguesia já identificou essa como uma grande oportunidade de ampliação de suas taxas de lucros, que vem sofrendo queda acentuada nas últimas décadas.

Para tal, os organismos internacionais apontam o baixo nível de escolaridade nos países periféricos como sendo a causa destes não conseguirem uma devida inserção na "nova ordem mundial" globalizada. Para atingir tais objetivos recomendam uma educação voltada para atender os interesses dos setores produtivos do capital.

Essa ampliação do acesso à educação superior deve se voltar, segundo estes organismos, para a "população mais pobre", sob uma diversificação maior das

\footnotetext{
${ }^{9}$ Para uma análise mais aprofundada ver Lima (2007; p. 51-76), Leher (2004) e Siqueira (2004).
} 
instituições de ensino superior ${ }^{10}$ e dos cursos de graduação, e ainda com formas alternativas de captação de recursos externos.

Cabe destacar que essa expansão do ensino superior se daria de duas formas que se completam: através da ampliação da rede privada, com o oferecimento de vagas a população mais pobre através de subsídios governamentais (PROUNI, FIES) e também da privatização "por dentro" das IFES (cursos autofinanciáveis, fundações de apoio institucional, REUNI, UAB) como poderemos verificar nas próximas seções.

Harvey (2003) nos revela o caráter importante desempenhado pela educação superior no projeto burguês, como vemos a seguir:

\begin{abstract}
"A produção de conhecimento passou por notável expansão nas últimas décadas, ao mesmo tempo que assumiu cada vez mais um cunho comercial (como provam as incômodas transições de muitos sistemas universitários do mundo capitalista avançado de guardiães do conhecimento e da sabedoria para produtores subordinados de conhecimento a soldo do capital corporativo)." (HARVEY, 2003; p. 151)
\end{abstract}

Outro aspecto que surge como pilar na estratégia dos organismos internacionais do capital é a utilização em larga escala dos recursos tecnológicos para promover a ampliação do acesso através de cursos à distância, a fim de superar o "analfabetismo tecnológico" e o chamado "desemprego tecnológico". Essa recomendação na verdade, acaba por criar mais uma frente para o investimento externo da burguesia dos países centrais, pois abre a possibilidade de venda de pacotes educacionais tecnológicos, na maioria dos casos, vindos desses países, assim como a utilização de equipamentos e mídias desenvolvidos por estes mesmos países, o que acarretará numa maior dependência tecnológica, controle da formação e controle do conhecimento.

Esse processo descrito acima, de ampliação do acesso ao ensino superior omite os reais objetivos do capital internacional, que, ao analisarmos o REUNI ficará claro como um aligeiramento da formação acadêmica voltada para as áreas ditas "produtivas" e a certificação em larga escala, com vistas à coesão social.

É importante frisar que este movimento de mão dupla entre os organismos internacionais do capital e as parcelas burguesas que dominam e governam os países periféricos é contínuo e incessante, apresentando desdobramentos ininterruptamente. Para efeito de análise neste trabalho, nos detemos em alguns

\footnotetext{
10 Segundo o Banco Mundial, o "modelo único" adotado para a educação superior no Brasil - o da indissociabilidade entre ensino, pesquisa e extensão - é muito caro, anacrônico e obsoleto (Banco Mundial, 1994).
} 
dos mais importantes documentos do Banco Mundial publicados até 2003, mas vale ressaltar que outros organismos internacionais, como a UNESCO e o FMI, participam deste processo e que hoje se destaca neste papel o Acordo de Bolonha $^{11}$, firmado em 1999 entre os Ministros da Educação de diversos países europeus a fim de padronizar o modelo de educação superior europeu, principalmente através da formação em ciclos, e que hoje ganhou força em diversos países do mundo, inclusive no Brasil.

\section{7 - O REUNI como Instrumento da Contra Reforma da Educação Superior}

O carro-chefe das medidas adotadas pelo governo Lula da Silva a fim de promover uma contra-reforma universitária de maneira fragmentada a fim de não chamar muito, foi sem dúvida alguma o REUNI. Enxergamos ainda este Decreto como sendo o marco de implementação do conceito de educação terciária defendido pelo Banco Mundial no documento de 2003, anteriormente analisado.

Segundo o MEC, o Programa de Apoio a Planos de Reestruturação e Expansão das Universidades Federais - REUNI, instituído pelo Decreto ํo 6.096, de 24/04/2007, tem como objetivos, oferecer às universidades federais as condições necessárias para ampliação do acesso e permanência no ensino superior, como uma das ações que tornam viável o PDE. O REUNI pretende implementar uma política de expansão do ensino superior público, que de acordo com o Ministério da Educação, - Brasil poderá cumprir o papel atribuído pelo PNE (Lei № 10.172/2001) que estabeleceu o aumento da oferta de ensino superior para, 30\% dos jovens na faixa etária de 18 a 24 anos, até 2010.

Assim, o REUNI tem como meta global a elevação gradual da taxa de conclusão média dos cursos de graduação presenciais para noventa por cento e da relação de alunos de graduação em cursos presenciais por professor para dezoito, ao final de cinco anos, a contar do início de cada plano.

A possibilidade desse incremento no ingresso está fortemente relacionada à razão de 18 estudantes de graduação, em cursos presenciais por professor,

\footnotetext{
11 Tal processo propôs e vem estabelecendo uma padronização quanto à duração dos cursos superiores, organizando-os em três ciclos, com as seguintes durações: $1^{\circ}$ ciclo, com até 3 anos, correspondente à graduação; 2ำ ciclo, com 2 anos, chamado de mestrado e o 3ำ ciclo, com 3 anos, sendo o doutorado. Em todos esses ciclos deveria haver um sistema de créditos transferíveis, acreditação/revalidação de títulos por agências nacionais, agências de certificação de qualidade, mas de preferência rumo a uma agência supranacional, européia e quiçá mundial, baseadas na avaliação de competências, definidas no sistema europeu de standards e guidelines- diretrizes; revalidação de títulos, mobilidade estudantil, etc. Bolonha também institucionalizou de cobrança de mensalidades/anuidades em todos os ciclos, mesmo em estabelecimentos oficiais onde não existia. Para aprofundar ver ROSA (sem data).
} 
colocada como uma das metas, logo no art. $1^{\circ}\left(\S 1^{1}\right.$ ). Historicamente, o número médio de estudantes de graduação por professor situa-se próximo a 9 nas IFES. Nos últimos três anos, esse número já vem aumentando bastante, sendo citado nos últimos dados do INEP, correspondente ao ano de 2005, como sendo de 10,9 (ANDES-SN, 2007; p. 24). É necessário não confundir a razão estudante/professor com o atendimento de estudantes pelos professores, ou seja, com o tamanho das classes de aula, que é muito maior em função de cada estudante cursar várias disciplinas simultaneamente. É necessário também considerar que o mesmo professor atende estudantes de pós-graduação, faz pesquisas, executa tarefas administrativas e supervisiona atividades de extensão.

Para uma real ampliação do acesso nas dimensões propostas, mas com qualidade, faz-se necessário, além da renúncia a índices irreais, um rápido aumento no financiamento público para a educação, como um todo, até alcançar a ordem de $10 \%$ do PIB, conforme previsto no PNE.

Treze anos depois da publicação do documento do BM "Educação superior: Lições Derivadas da Experiência" o REUNI apresenta no seu artigo primeiro a mesma centralidade no ensino de graduação defendida em 1994 pelo Banco Mundial:

Art. 1ำ Fica instituído o Programa de Apoio a Planos de Reestruturação e Expansão das Universidades Federais - REUNI, com o objetivo de criar condições para a ampliação do acesso e permanência na educação superior, no nível de graduação, pelo melhor aproveitamento da estrutura física e de recursos humanos existentes nas universidades federais.

$\S 1^{\circ}$ O Programa tem como meta global a elevação gradual da taxa de conclusão média dos cursos de graduação presenciais para noventa por cento e da relação de alunos de graduação em cursos presenciais por professor para dezoito, ao final de cinco anos, a contar do início de cada plano.

Em relação à otimização das instalações físicas das IFES, devemos frisar que o problema está relacionado diretamente com o financiamento insuficiente para obras e para aquisição de material. Para tal, o Decreto aponta a necessidade de redução da evasão e a ocupação de vagas ociosas, principalmente no período noturno.

Art. $2^{\circ} \mathrm{O}$ Programa terá as seguintes diretrizes:

I - redução das taxas de evasão, ocupação de vagas ociosas e aumento de vagas de ingresso, especialmente no período noturno;

Ainda segundo o MEC, o REUNI não preconiza a adoção de um modelo único para a graduação das universidades federais, já que tem como premissa respeitar a 
autonomia universitária e a diversidade das instituições, como também preconiza o Banco Mundial. Os projetos apresentados pelas universidades poderão iniciar-se no conjunto de suas unidades acadêmicas, e em novas unidades a serem criadas (expansão), desde que, ao final do período de cinco anos (2012), a meta estabelecida seja alcançada. Aqui também podemos apreender as diretrizes do BM, visto que, a criação de centros de excelência em pesquisa nos grandes pólos regionais e a interiorização de cursos de graduação sem nenhuma associação com a pesquisa e a extensão universitária, é uma realidade nos marcos do REUNI, como analisaremos adiante.

O MEC afirma que junto com a ampliação do acesso, o melhor aproveitamento da estrutura física e o aumento do qualificado contingente de recursos humanos existente nas universidades federais, está também a preocupação de garantir a qualidade da graduação da educação pública, $O$ Ministério afirma que isto é fundamental para que os "diferentes percursos acadêmicos oferecidos possam levar à formação de indivíduos aptos a enfrentar os desafios do mundo contemporâneo, em que a aceleração do processo de conhecimento exige profissionais com formação ampla e sólida" (MEC, 2007; p. 5). Não é o que parece ao verificarmos que o Reuni prepara todo o caminho para a desestruturação do modelo atual de universidade para a implantação de um modelo de instituições diversificadas, quebrando o tripé ensino-pesquisa-extensão, contribuindo para uma formação aligeirada, acrítica e voltada para a conformação dos futuros profissionais a nova realidade imposta pelo capital.

Nas diretrizes do Plano, a mobilidade estudantil surge como uma primordial meta a ser atingida pelas IFES que aderiram ao REUNI "por se constituir em estratégia privilegiada de construção de novos saberes e de vivência de outras culturas, de valorização e de respeito ao diferente" (MEC, 2007; p. 5). Para o governo brasileiro, o exercício profissional no mundo atual requer aprendizagens múltiplas e demanda interseção com saberes e atitudes construídos a partir de experiências diversas que passam a ser, cada vez mais, objeto de valorização na formação universitária. Entretanto, a existência efetiva de programas de mobilidade impõe não só condições materiais para que os estudantes se façam presentes em outras instituições.

Art. 2응 $\mathrm{O}$ Programa terá as seguintes diretrizes: 
II - ampliação da mobilidade estudantil, com a implantação de regimes curriculares e sistemas de títulos que possibilitem a construção de itinerários formativos, mediante o aproveitamento de créditos e a circulação de estudantes entre instituições, cursos e programas de educação superior; III - revisão da estrutura acadêmica, com reorganização dos cursos de graduação e atualização de metodologias de ensino-aprendizagem, buscando a constante elevação da qualidade;

Segundo o MEC, é necessário, sobretudo, "superar o problema do distanciamento entre as instituições de ensino, estimulando uma cultura de cooperação permanente e garantindo ao aluno o aproveitamento dos conteúdos estudados" (MEC, 2007; p. 5-6). Entretanto, não se vê nenhum incentivo por parte do governo federal a fim de conceder algum tipo de auxílio aos estudantes para que estes possam se locomover, alimentar e muito menos se alojarem nas diversas IFES.

\section{8 - Considerações Finais}

Essa lógica perversa pode ser perfeitamente identificada na contra-reforma universitária implementada pelo governo Lula da Silva de forma salteada, dividida em decretos diversos, que por fim atende em cheio aos objetivos dos organismos internacionais. O REUNI, em especial, transplanta todas essas orientações para as ações práticas do governo como, por exemplo: i) a padronização dos cursos através da uniformização de conteúdos e da articulação dos vários níveis de ensino; e ii) a transformação das universidades em repetidoras de tecnologias desenvolvidas de fora para dentro, formando trabalhadores voltados apenas pra atender aos interesses do capital.

A tudo isso dito anteriormente dito, se articula a grande dificuldade imposta aos docentes por todas essas medidas adotadas pelo governo brasileiro ao atender ao aceno dos organismos internacionais. Os mestres têm a autonomia "compartilhada" por programas anteriormente direcionados, currículos prédeterminados, apoio técnico e financeiro para desenvolver pesquisas vinculado à editais de fomento das agências de pesquisa, acúmulo de tarefas extraclasse que beiram ao absurdo, culminando com o adoecimento e até a invalidez permanente. Ainda podemos citar o fato do aumento desenfreado do número de alunos por sala de aula que colabora com a queda da qualidade do ensino prestado, a reposição insuficiente dos quadros docentes das IFES, a expansão a "toque de caixa" para o interior sem nenhum critério técnico (apenas político), a ingerência sobre a 
administração das universidades através de contratos de gestão, que ficam reféns de metas pré estabelecidas pelo MEC.

\section{REFERÊNCIAS BIBLIOGRÁFICAS}

ANDES-SN. As novas faces da reforma universitária do governo Lula e os impactos do PDE sobre a educação superior. Cadernos ANDES nํ⒉ Brasília, DF. Agosto 2007.

BANCO MUNDIAL. 1994. La Enseñanza Superior - Lãs Lecciones derivadas de La Experiência. Washington, 1994. Disponível em www.bancomundial.org.br acessado em maio/2009.

. Prioridades y estratégias para la educación. Washington, D.C: Banco Internacional de Reconstrucción y Fomento / Banco Mundial, 1996.

. Estratégia para o Setor Educacional. Washington D.C.

Banco Internacional para Reconstrução e Desenvolvimento / Banco Mundial, 1999.

Construir Sociedades de Conocimiento: Nuevos Desafios para La Educación Terciaria. Washington D.C. Banco Internacional para Reconstrução e Desenvolvimento / Banco Mundial, 2003.

. MINISTÉRIO DA EDUCAÇÃO. Diretrizes Gerais do REUNI - Agosto de

2007. Disponível em http://portal.mec.gov.br/sesu/arquivos/pdf/diretrizesreuni.pdf - consultado em 17.08.2008

BRASIL - Presidência da República - Decreto nำ6.096, Brasília, 2007. Disponível em http://www.dee.ufcg.edu.br/dee/arquivos/Decreto.6096.de.24.04.2007.pdf consultado em 17.08.2008.

CHOSSUDVSKY, Michel. A globalização da pobreza: impactos da reforma do FMI e do Banco Munidal. 1ª Edição. Editora Moderna. São Paulo, 1999.

FONSECA, Marília. O Financiamento do Banco Mundial à Educação Brasileira: vinte anos de cooperação internacional. In: DE TOMASSI, L., WARDE, M. J. e Haddad, J. (orgs.) O Banco Mundial e as Políticas Educacionais. São Paulo: Cortez, 2000. p. 229-251.

HARVEY, David. Condição pós-moderna: Uma pesquisa sobre as origens da mudança cultural. São Paulo: Loyola, 2003.

\section{O novo imperialismo. São Paulo: Loyola, 2004.}

LEHER, Roberto e BARRETO, Raquel Goulart. Do discurso e das condicionalidades do Banco Mundial, a educação superior "emerge" terciária. In Revista Brasileira de Educação, v. 33, no 39, set/dez 2008; p. 423436.

LEHER, Roberto. Reforma Universitária do governo Lula: retorno do protagonismo do Banco Mundial e das lutas anti-neoliberais. 6 fev., 2004. Disponível em: http://www.adur-ri.org.br/5com/popup/Reforma universit governo LULA.htm.

LIMA, Kátia S. Contra-Reforma na Educação Superior: de FHC a Lula. São Paulo: Xamã, 2007.

OLIVEIRA, Marcos Marques de . A política governamental de ciência e tecnologia: da C\&T à CT\&I. In NEVES, L. M. W. O empresariamento da educação. São Paulo. Ed. Xamã, 2002. 
ROSA, Rui Namorado. Ensino superior: a reforma ditada pela União Européia. Disponível em http://resistir.info/rui/educacao ameacada 5.html Acesso em 28 de Julho de 2010. Sem data.

SIQUEIRA, Ângela C. Organismos Internacionais, Gastos Sociais e Reforma Universitária do Governo Lula In: NEVES, Lucia M. W. (org.) Reforma Universitária do Governo Lula: reflexões para o debate. São Paulo: Xamã, 2004. TOUSSAINT, Eric. Banco Mundial El Golpe de Estado Permanente: La Legenda Oculta del Consenso de Washington. Quito: Abya Yala, 2007.

UGÁ, Vivian D. A Categoria "Pobreza" nas Formulações de Política Social do Banco Mundial. In: Revista Sociologia Política. Curitiba, n.23, Nov/2004. p. 5562. 